\title{
Colonization of Gnotobiotic Mice with Human Gut Microflora at Birth Protects Against Escherichia coli Heat-Labile Enterotoxin-Mediated Abrogation of Oral Tolerance
}

\author{
VALÉRIE GABORIAU-ROUTHIAU, PIERRE RAIBAUD, CATHERINE DUBUQUOY, AND \\ MARIE-CHRISTIANE MOREAU
}

Unité d'Ecologie et de Physiologie du Système Digestif. INRA, 78352 Jouy-en-Josas Cedex, France

\begin{abstract}
ABST
Previous work has shown that the indigenous gut microflora
in mice plays a protective role against Escherichia coli heat-
labile enterotoxin (LT)-mediated abrogation of oral tolerance to
an unrelated co-ingested protein. To assess potential protection
by human gut microflora, we studied the effect of human gut
microflora in a murine model. Oral tolerance was studied in adult
gnotobiotic mice (i.e. ex-germ-free mice) colonized with the
entire human fecal microflora and orally administered once with
LT and ovalbumin. Systemic suppression of IgG, IgG1, IgG2a,
and IgE antibody responses was assessed by ELISA. Both spe-
cific IgG subclasses and IgE hyporesponsiveness was induced in
LT + ovalbumin-fed gnotobiotic mice, indicating that the hu-
man gut microflora can protect against the LT-mediated abroga-
tion of oral tolerance. However, as confirmed with mouse gut
microflora, this protective effect only occurs when the gut mi-
croflora is associated from birth on. Colonization of germ-free
mice with a single bacterial strain, E. coli, predominant in the
human and mouse gut microflora in the neonatal period, showed
that this strain alone did not induce protection. These results
\end{abstract}
The gut mucosal immune system is exposed to numerous environmental Ag, but it is important that it does not mount immune responses against harmless or potentially beneficial $\mathrm{Ag}$ such as food and commensal bacteria. The intestinal immune system has developed the ability to induce a profound systemic immunologic unresponsiveness to orally administered soluble Ag. Such unresponsiveness, termed "oral tolerance," is believed to be of physiologic significance for food proteins $(1,2)$. Food-allergic diseases, most common in in-

Received July 25, 2002; accepted April 26, 2003.

Correspondence: Valérie Gaboriau-Routhiau, Unité d'Ecologie et de Physiologie du Système Digestif. Bât 440, INRA, 78352 Jouy-en-Josas Cedex, France; e-mail: routhiau@jouy.inra.fr

Supported by a grant from the Danone Institute, Levallois-Perret, France.

DOI: 10.1203/01.PDR.0000086902.52137.C9 supported the hypothesis that the natural establishment of the gut microflora in neonates crucially influenced resistance to LTmediated abrogation of oral tolerance by reinforcing suppression of both $\mathrm{T}$ helper type $1-$ and $\mathrm{T}$ helper type 2 -controlled responses, and suggested that sequential bacterial colonization of the gut rather than a single bacterial species may be involved in this phenomenon. (Pediatr Res 54: 739-746, 2003)
Ab, antibody
Abbreviations
Ag, antigen
Bic, bicarbonate
$\mathbf{C V}$, conventional
GALT, gut-associated lymphoid tissue
GF, germ-free
LT, Escherichia coli heat-labile enterotoxin
OVA, ovalbumin
Th, T helper

fancy, may thus represent a breakdown or failure of oral tolerance induction or maintenance.

Among the environmental factors that affect the induction of oral tolerance, bacterial enterotoxins are major ones. It has been reported that in mice, the two related enterotoxins, cholera toxin and LT, responsible for numerous diarrheas in human infants and adults, abrogate oral tolerance induction to a simultaneously ingested protein Ag when estimated using the serum Ag-specific IgG and IgE Ab levels (3-7). This toxinmediated abrogative effect (or adjuvant effect) may result from a direct effect on Ag-presenting cells and $\mathrm{T}$ cells through modulation of surface marker expression, such as B7.2 and/or CD40 ligand, and modulation of Th1- and Th2-type cytokines provided from mucosal and systemic immune compartments, which may affect subsequent development of Th1- or Th2-type 
immune responses $(8-11)$. We observed that $\mathrm{CV}$ mice are less sensitive to LT-mediated abrogation of oral tolerance than GF mice. Whereas two oral doses of $10 \mu \mathrm{g}$ of LT administered simultaneously with $20 \mathrm{mg}$ of OVA are required to abrogate anti-OVA IgG and IgE Ab suppression in CV mice, only one dose is effective in GF mice and may prime mice for subsequent $\mathrm{Ab}$ responses, thus suggesting that the indigenous gut microflora plays a protective role (6). Because of the possible consequences of enterotoxin on human hypersensitivity to dietary proteins, we tested whether the human gut microflora could protect against the LT-mediated effect on oral tolerance, without any relationship between infection of human newborns with $E$. coli producing LT and development of food allergies later in life being presently known.

Early life is thought to play a crucial role in the development of dietary hypersensitivities. A lack of exposure to bacteria and infections in childhood has been suggested to be one of the factors involved in the increased occurrence of allergies in children (12-15). In the present study, we investigated the influence of the neonatal period on the development of protection by testing the protective role of human gut microflora when it colonizes the gut either at birth or later, at the adult stage. Moreover, we investigated whether bacteria present in large amounts in the gut microflora in early life could prevent LT-mediated abrogation of oral tolerance. The experiments were performed using gnotobiotic mice, i.e. ex-GF mice, colonized with either the whole fecal microflora from a healthy adult human or a single bacterial strain predominant in neonates: E. coli. The influence of LT on oral tolerance to coadministered OVA was assessed by serum anti-OVA IgG and $\mathrm{IgE} \mathrm{Ab}$ responses. To gain insight into the potential mechanisms by which the gut microflora might protect against LTmediated abrogation of oral tolerance, we examined the Th1/ Th2 balance as evaluated on the basis of the serum Th1- and Th2-associated isotypes IgG2a and IgG1, respectively (16).

Our data indicated that the human gut microflora prevented LT-mediated abrogation of oral tolerance only if the gut microflora was present from birth on, and protection may result from suppression of both Th1- and Th2-controlled responses. Moreover, natural sequential bacterial colonization of the gut as of the neonatal period may be more important to this phenomenon than the influence of particular bacterial species predominant in neonates.

\section{MATERIALS AND METHODS}

Mice. Animal experiments were carried out with GF $\mathrm{C} 3 \mathrm{H} / \mathrm{He}$ mice bred at the breeding facility of INRA, in accordance with the regulations of the Animal Care Committee of INRA. Both GF and gnotobiotic mice were bred in a Trexler plastic isolator (La Cahlène, Vélizy, France) and fed ad libitum on a sterile OVA-free diet (6). All procedures were carried out in accordance with the European guidelines for the care and use of laboratory animals.

Bacterial inoculum and infection of mice. GF mice were colonized with a human fecal microflora, either from birth on (neonatal stage) or at $5 \mathrm{wk}$ of age (adult stage). To obtain mice associated with human microflora at the neonatal stage, parent
GF mice were colonized with human microflora so that their offspring were naturally colonized with this microflora at birth. For colonization at the adult stage, mice were orally inoculated twice at a $24-\mathrm{h}$ interval with $0.5 \mathrm{~mL}$ of a $10^{-2}$ fresh human fecal homogenate prepared and kept for $24 \mathrm{~h}$ in an anaerobic glove box (17). Similarly, GF adult mice were colonized with a CV adult mouse fecal microflora.

In parallel, GF mice were monoassociated either at the neonatal or the adult stage with a strain of $E$. coli isolated from $\mathrm{CV}$ mouse fecal microflora. The strain of $E$. coli was isolated from a $10^{-4}$ fecal dilution cultured selectively on a solid desoxycholate agar medium (Difco, BD Biosciences, Le Pont de Claix, France) incubated at $37^{\circ} \mathrm{C}$ for $2 \mathrm{~d}$ under aerobic conditions. Then, adult GF mice were inoculated with $0.5 \mathrm{~mL}$ of a 24-h culture of the strain in liquid LB broth (Difco) at $37^{\circ} \mathrm{C}$ under aerobic conditions. This strain was tested to ensure that it did not produce LT in comparison with the enterotoxigenic E. coli strain H10407, kindly provided by Dr. M Levine (University of Maryland, Baltimore, MD, U.S.A.). Briefly, as adult mice colonized with the enterotoxigenic $E$. coli did not develop diarrhea, LT synthesis in vivo was tested by assaying anti-LT IgG Ab in serum of gnotobiotic mice colonized with either the enterotoxigenic strain or our E. coli strain, by ELISA. Mice colonized with our strain did not develop any anti-LT response, in contrast to others, suggesting that our $E$. coli strain is not enterotoxigenic (data not shown).

Bacterial analysis. Characterization of the predominant human microflora (i.e. $\geq 10^{8}$ bacteria/g of intestinal content) in both human fecal samples and feces of gnotobiotic mice colonized either from birth on or at the adult stage was performed using standard bacterial culture methods and morphologic examination of 100 isolated colonies representative of the cultivable predominant microflora (17-19). Briefly, the colonies were selected at random among colonies cultured $5 \mathrm{~d}$ at $37^{\circ} \mathrm{C}$ under anaerobic conditions on a nonselective prereduced solid brain heart infusion medium (BHI; Difco) supplemented with $0.5 \%$ yeast extract (Difco) and $5 \mathrm{mg} / \mathrm{L}$ of hemin (Sigma Chemical Co., St. Quentin Fallavier, France) (BHI-H), and inoculated with $0.1 \mathrm{~mL}$ of the $10^{-8}$ fecal dilution. For further characterization, the 100 isolated colonies were subcultured on BHI-H Petri dishes. Their subsequent classification into bacterial groups was performed on the basis of cell morphology, motility, spore formation, and catalase production on BHI-H, Gram characteristics, and oxygen sensitivity (17, 18). Bacterial count for each genus identified was obtained by multiplying the total bacterial count on $\mathrm{BHI}-\mathrm{H}$ by the frequency of each genus among the 100 colonies tested. In addition, in parallel with the initial cultivation on the nonselective BHI-H medium and to potentially enumerate subdominant microflora, some bacterial counts were performed on selective media. Enterobacteria were enumerated on a desoxycholate agar medium (Difco) and facultative anaerobic streptococci on BHI-H supplemented with $30 \mathrm{mg} / \mathrm{L}$ of sodium azide (Prolabo, Fontenay-sous-Bois, France), both grown at $37^{\circ} \mathrm{C}$ for $2 \mathrm{~d}$ under aerobic conditions. Bifidobacterium sp. and lactobacilli were enumerated on a solid lactobacilli MRS broth medium (pH 5.4, Difco) after incubation at $37^{\circ} \mathrm{C}$ for $5 \mathrm{~d}$ under 
anaerobic conditions. Their further differentiation was performed by both morphology and colony examination.

Induction and assessment of oral tolerance. To study the LT-mediated effect on oral tolerance induction, gnotobiotic female mice were used at $8 \mathrm{wk}$ of age. Three groups of mice (7-10 mice per group) were fed and immunized as previously described (6). Briefly, mice were fed once on d 0 either with 20 mg of OVA (grade V, Sigma Chemical Co.) (tolerant group), or $10 \mu \mathrm{g}$ of LT $+20 \mathrm{mg}$ of OVA (LT from ICN Biochemicals, Orsay, France) (experimental group) or bicarbonate buffer only (Bic; Prolabo) (control group). Seven and $21 \mathrm{~d}$ later, all mice were immunized i.p. with OVA as follows: First with $10 \mu \mathrm{g}$ of OVA absorbed by $1 \mathrm{mg}$ of alum (Pierce, Interchim, Montluçon, France) and then with $50 \mu \mathrm{g}$ of OVA in $4 \mathrm{mg}$ of alum. Mice were bled on d 30 and sera were stored at $-20^{\circ} \mathrm{C}$ until use.

Detection of serum antibodies. Serum anti-OVA Ab responses were assayed by ELISA. The anti-OVA IgG and IgE responses were assayed as previously described (6). Briefly, microtiter plates were coated overnight at $4^{\circ} \mathrm{C}$ with OVA. Bound anti-OVA Ab were revealed with horseradish peroxidase-conjugated anti-mouse $\operatorname{IgG}$ or IgE, respectively (P.A.R.I.S, Compiègne, France). The specificity of the antimouse $\operatorname{IgE} \mathrm{Ab}$ was tested by the reactivity with myeloma $\operatorname{IgE}$ proteins, but not with $\operatorname{IgG} 1, \operatorname{IgG} 2 \mathrm{a}, \operatorname{IgG} 2 \mathrm{~b}, \operatorname{IgG} 3, \operatorname{IgM}, \operatorname{IgA}$, and $\operatorname{IgD}$ myeloma proteins in a solid-phase ELISA test (data not shown). Labeled $\mathrm{Ab}$ were revealed with $o$-phenylenediamine (Sigma Chemical Co.) or 3,3',5,5'-tetramethylbenzidine peroxidase substrate (Labsystem, Cergy-Pontoise, France), and absorbances were measured at 490 or $450 \mathrm{~nm}$, respectively. IgG concentration in each sample was calculated with reference to purified polyclonal mouse anti-OVA $\operatorname{IgG} \mathrm{Ab}$, and anti-OVA IgE titers were expressed as (OD ratio of sample to standard at $1 / 40$ th dilution) $\times 100$.

To detect both IgG2a and IgG1 Abs, the 96-well plates (Immunlon II, Labsystem) were coated overnight at $4{ }^{\circ} \mathrm{C}$ with $100 \mu \mathrm{L}$ of a 10 or $5 \mu \mathrm{g} / \mathrm{mL}$ solution of OVA (ImjectOVA, Pierce) in $0.1 \mathrm{M}$ bicarbonate buffer, respectively. After washes with PBS- $0.05 \%$ Tween 20 (PBS-Tw; Sigma Chemical Co.), nonspecific binding sites were blocked with $100 \mu \mathrm{L} /$ well of PBS-1\% BSA (Sigma Chemical Co.) for $1 \mathrm{~h}$ at $37^{\circ} \mathrm{C}$. The plates were then incubated first with $50 \mu \mathrm{L}$ aliquots of test sample in PBS-Tw for $2 \mathrm{~h}$ at $37^{\circ} \mathrm{C}$. Secondly, peroxidaseconjugated rat anti-mouse IgG2a or IgG1 (both from BD PharMingen, San Diego, CA, U.S.A.) both diluted 1:2000 in PBS-Tw were added at $100 \mu \mathrm{L} /$ well and incubated for $2 \mathrm{~h}$ at $37^{\circ} \mathrm{C}$. Finally, $100 \mu \mathrm{L}$ of 3,3',5,5'-tetramethylbenzidine peroxidase substrate (Labsystem) were added to each well. The reaction was stopped with $50 \mu \mathrm{L} /$ well of $4 \mathrm{M} \mathrm{H}_{2} \mathrm{SO}_{4}$ and plates were read at $450 \mathrm{~nm}$ using an automatic Multiskan microplate reader (Labsystem).

Statistical analyses. Data are expressed as individual values or means \pm SEM, for groups of 7-10 mice. Variances were homogenized by logarithmic transformation and statistical differences were analyzed using the two-tailed $t$ test. Differences were considered statistically significant at $p$ values of 0.05 . Given that five independent experiments were carried out, i.e. human flora or E. coli at neonatal or adult stage and mouse flora at adult stage, data were compared only within each experiment. Data are representative of two similar experiments.

\section{RESULTS}

The protective role of the human gut microflora depends on the stage at which mice are colonized. To test the potential protective role of the human fecal microflora against LTmediated abrogation of oral tolerance, induction of oral tolerance was first estimated in (LT + OVA)-fed gnotobiotic mice colonized with human gut microflora at the adult stage (i.e. 5 wk of age), by quantification of serum IgG and IgE anti-OVA $\mathrm{Ab}$ on $\mathrm{d}$ 30, i.e. $9 \mathrm{~d}$ after the second i.p. immunization with OVA. As shown in Figure $1 A$, there was no difference in the anti-OVA IgG levels between (LT + OVA)- and control Bic-fed groups, whereas levels for both were significantly higher than those of the tolerant OVA-fed group $(p<0.001)$. When we assessed the anti-OVA IgE response in the (LT + OVA)-fed mice, they exhibited a partial abrogation of the response (Fig. $1 B$ ). The anti-OVA IgE titer was significantly higher than that in the OVA-fed mice $(p<0.001)$ and significantly lower than that in the Bic-fed mice $(p<0.001)$. This data thus reflected the LT-mediated abrogation of oral tolerance and suggested that the human gut microflora may not exert any protective effect.

As the protective effect of the mouse gut microflora has previously been observed in $\mathrm{CV}$ mice naturally colonized with
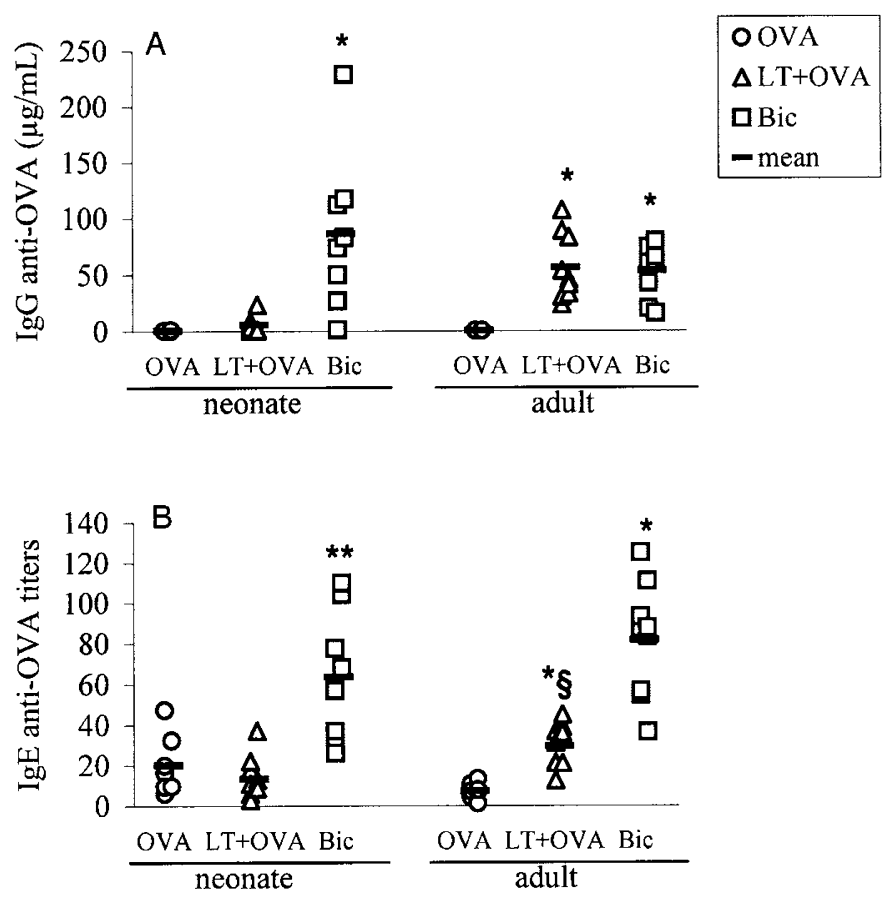

Figure 1. Systemic anti-OVA $\operatorname{IgG}(A)$ and $\operatorname{IgE}(B)$ responses in gnotobiotic mice colonized with human gut microflora at the adult stage (adult) or at the neonatal stage (neonate). Mice (7-10 per group) were fed once either with OVA, or LT + OVA or bicarbonate (Bic) buffer on d 0 . Then, they were immunized i.p. with OVA twice, on $\mathrm{d} 7$ and $\mathrm{d} 21$. The anti-OVA IgG Ab levels $(\mu \mathrm{g} / \mathrm{mL}$ of serum) and the $\operatorname{IgE} \mathrm{Ab}$ titers were assayed by ELISA in serum collected on d 30. Individual data are represented and horizontal bars indicate the mean for each group. ${ }^{*} p<0.001,{ }^{*} p<0.01$ compared with the respective OVA-fed group, and $\S p<0.001$ compared with the respective Bic-fed group. 
gut microflora from birth on (6), we wanted to determine whether the presence of human gut microflora from the neonatal period on could influence its protective effect. Induction of oral tolerance was then assessed in (LT + OVA)-fed mice born of gnotobiotic parents and naturally colonized with human fecal microflora at the neonatal stage. Figure 1, $A$ and $B$, shows that both anti-OVA IgG and IgE responses detected in the (LT + OVA)-fed group were significantly lower than those of the control Bic-fed group $(p<0.001$ and $p<0.01$, respectively) and did not differ from those of the tolerant OVA-fed group. This reflected the induction of oral tolerance and a protective role of the human gut microflora under these experimental conditions.

In contrast, when the gut microflora from these adult gnotobiotic mice colonized with human gut microflora at the neonatal stage was inoculated to another group of GF adult mice (5 wk of age), no protective effect against the LTmediated abrogation of oral tolerance to OVA was observed. Both $\mathrm{IgG}$ and $\mathrm{IgE} \mathrm{Ab}$ responses in the (LT + OVA)-fed group were not significantly different from those of the Bic-fed group (data not shown). This data suggested the importance of the role of the gut microflora at the neonatal period rather than a difference in the bacterial composition of the gut microflora in adults for protection against the LT-mediated effect on oral tolerance.

Mouse gut microflora inoculated in adults does not protect against LT-mediated abrogation of oral tolerance. To confirm the key role of the establishment of the gut microflora at the neonatal period and to prove that the previous results were not related to the human gut microflora, experiments were performed in gnotobiotic mice colonized at an adult stage with the gut microflora from a CV adult mouse (Fig. 2). In (LT + OVA)-fed mice, both OVA-specific IgG and IgE responses were significantly higher than those of tolerant OVA-fed control mice $(p<0.001)$. The OVA-specific IgG Ab response of (LT + OVA)-fed mice was also significantly lower than that of the Bic-fed control mice $(p<0.01)$, whereas the $\operatorname{IgE} \mathrm{Ab}$ responses were not significantly different between these two groups. These results indicated that oral tolerance to OVA was abrogated, at least partially, under these conditions and confirmed the data obtained with human gut microflora.

Similar predominant microflora in feces from adult gnotobiotic mice colonized with human fecal microflora either from birth on or at the adult stage. Because of the markedly different results between the two gnotobiotic models colonized with human gut microflora either at the neonatal or adult stage (i.e. $5 \mathrm{wk}$ of age), we characterized the predominant microflora in feces of 10-12-wk-old gnotobiotic mice of both models. Moreover, to validate the use of gnotobiotic mice in studying the protective role of human gut microflora, we performed similar bacteriological studies on the human donor's fecal sample. As reported in Table 1, no major difference was observed in the predominant fecal microflora between adult gnotobiotic mice colonied with the human microflora either at the adult or at the neonatal stage. Similar levels of the main bacterial genera were observed. Strictly anaerobic bacteria dominated, whereas facultative anaerobes, i.e. enterobacteria and streptococci, were subdominant. Hence, these results sup-
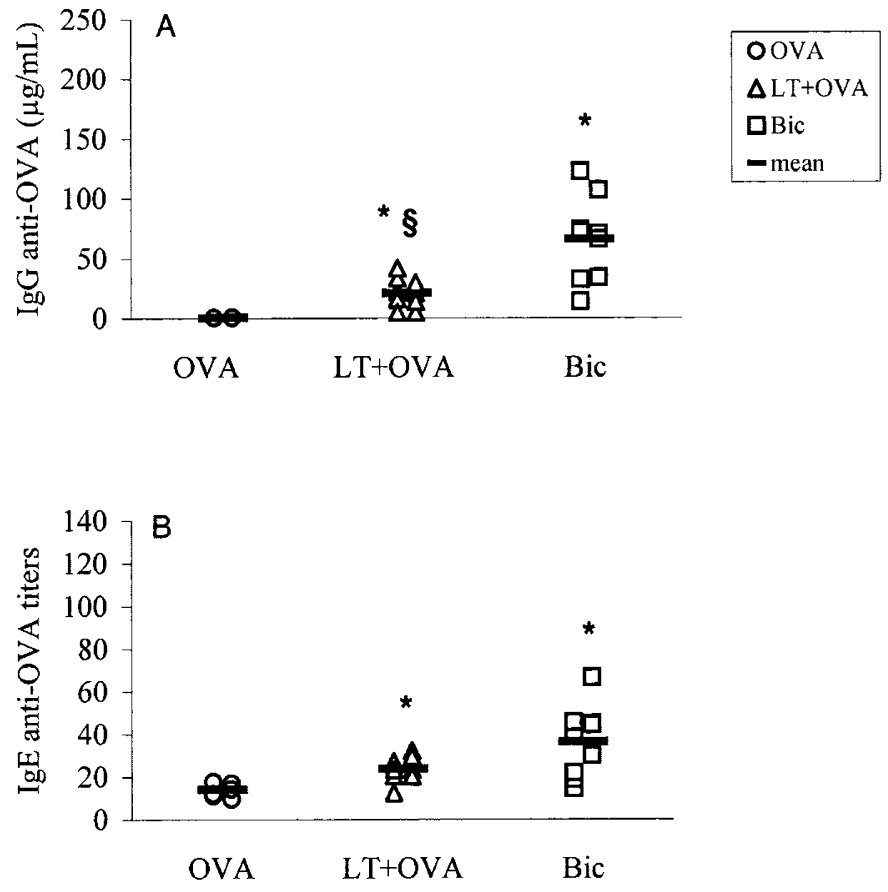

Figure 2. Systemic anti-OVA $\operatorname{IgG}(A)$ and $\operatorname{IgE}(B)$ responses in gnotobiotic mice colonized with mouse gut microflora at the adult stage. Mice were treated and results are expressed as in Figure 1. ${ }^{*} p<0.001$ compared with the OVA-fed group and $\S p<0.01$ compared with the Bic-fed group.

ported the hypothesis that the time of bacterial association in the digestive tract is much more important for the protective effect of the human gut microflora against the LT-mediated abrogation of oral tolerance than the bacterial composition of the gut microflora in adults. In contrast, bacterial analyses performed before weaning in 15-d old gnotobiotic mice colonized with the human microflora from birth on showed that bacterial diversity substantially differed from that of adults (Table 1). The predominant microflora was essentially composed of facultative anaerobic enterobacteria (mainly E. coli), whereas most strictly anaerobic bacteria were absent or present in smaller numbers than in adults, except for the Bacteroides sp. These differences might contribute to the importance of the neonatal period.

Similar total bacterial counts were obtained between human stools and feces from gnotobiotic mice at about $10^{10}$ bacteria/g of feces. The bacterial composition of the microflora in human samples and feces from adult gnotobiotic mice differed little, especially in enterobacteria and streptococci, which slightly decreased in gnotobiotic mice. Both bifidobacteria and lactobacilli were no longer detected in adult gnotobiotic mice. Nonetheless, the other bacterial groups were present in both samples.

E. coli does not protect against LT-mediated abrogation of oral tolerance irrespective of the time of colonization. To further investigate the importance of the neonatal period, we tested whether a single bacterial species present in large numbers in this period could be involved in protecting against the LT-mediated effect on oral tolerance. As shown in Table 1, E. coli predominated in 15-d-old gnotobiotic mice colonized with human gut microflora from birth on. Therefore, we studied the 
Table 1. Comparison of the microflora in adult human stools and feces from gnotobiotic mice colonized with human fecal microflora either at adult or neonatal stages

\begin{tabular}{|c|c|c|c|c|}
\hline \multirow[b]{3}{*}{ Bacterial genera } & \multicolumn{4}{|c|}{ No. of bacteria/g of feces } \\
\hline & \multirow[b]{2}{*}{ Human } & \multirow{2}{*}{$\begin{array}{c}\begin{array}{c}\text { Gnotobiotic mice } \\
\text { Adult stage }\end{array} \\
\text { Adult mice }\end{array}$} & \multicolumn{2}{|c|}{$\begin{array}{l}\text { Gnotobiotic mice } \\
\text { Neonatal stage }^{\mathrm{a}}\end{array}$} \\
\hline & & & Adult mice & 15-d-old mice \\
\hline Bacteroides sp. ${ }^{\mathrm{c}}$ & $1.5 \times 10^{10}$ & $1.5 \times 10^{10}$ & $1 \times 10^{10}$ & $5 \times 10^{9}$ \\
\hline Eubacterium sp. ${ }^{\mathrm{c}}$ & $1 \times 10^{10}$ & $6 \times 10^{9}$ & $7 \times 10^{9}$ & $1.8 \times 10^{8}$ \\
\hline Clostridium sp. ${ }^{\mathrm{c}}$ & $1 \times 10^{9}$ & $3 \times 10^{9}$ & $3 \times 10^{9}$ & $1.8 \times 10^{8}$ \\
\hline Peptostreptococcus sp. ${ }^{\mathrm{c}}$ & $1 \times 10^{10}$ & $1 \times 10^{10}$ & $4 \times 10^{9}$ & $<10^{8}$ \\
\hline Bifidobacterium sp. ${ }^{\mathrm{c}}$ & $2 \times 10^{9}$ & $<10^{3}$ & $<10^{3}$ & $<10^{3}$ \\
\hline Enterobacteria $^{\mathrm{b}, \mathrm{d}}$ & $1.8 \times 10^{8}$ & $4 \times 10^{7}$ & $4 \times 10^{6}$ & $1 \times 10^{10}$ \\
\hline Streptococcus sp. ${ }^{\mathrm{d}}$ & $2.9 \times 10^{8}$ & $6 \times 10^{7}$ & $3 \times 10^{7}$ & $2 \times 10^{9}$ \\
\hline Lactobacillus sp. ${ }^{\mathrm{d}}$ & $1.2 \times 10^{7}$ & $<10^{3}$ & $<10^{3}$ & $<10^{3}$ \\
\hline Total microflora & $3.8 \times 10^{10}$ & $3.4 \times 10^{10}$ & $2.4 \times 10^{10}$ & $1.7 \times 10^{10}$ \\
\hline
\end{tabular}

${ }^{a}$ Bacterial analyses were performed in both 15 -d-old mice and adult mice (i.e., $10-12$ wk old).

${ }^{\mathrm{b}}$ Mainly Escherichia coli as enumerated on desoxycholate agar medium.

${ }^{\mathrm{c}, \mathrm{d}}$ Strictly anaerobic bacteria and facultative anaerobic bacteria, respectively.

role of E. coli and assessed $\operatorname{IgG}$ and $\operatorname{IgE}$ Ab responses in gnotobiotic mice monoassociated with $E$. coli either at the neonatal or the adult stage. Bacterial counts were similar in the two gnotobiotic models at about $10^{10}$ bacteria/g of feces. As shown in Figure 3, significantly higher anti-OVA IgG and IgE $\mathrm{Ab}$ responses were detected in mice fed with (LT + OVA) compared with tolerant OVA-fed mice $(p<0.001$ and $p<$ 0.05 , respectively) irrespective of the stage at which mice were monoassociated with $E$. coli (i.e. neonatal or adult stage). In $E$. coli-monoassociated mice colonized at the adult stage, (LT + OVA)-feeding induced a significantly higher level of both anti-OVA IgG and IgE Ab than Bic-feeding, as the Ab levels
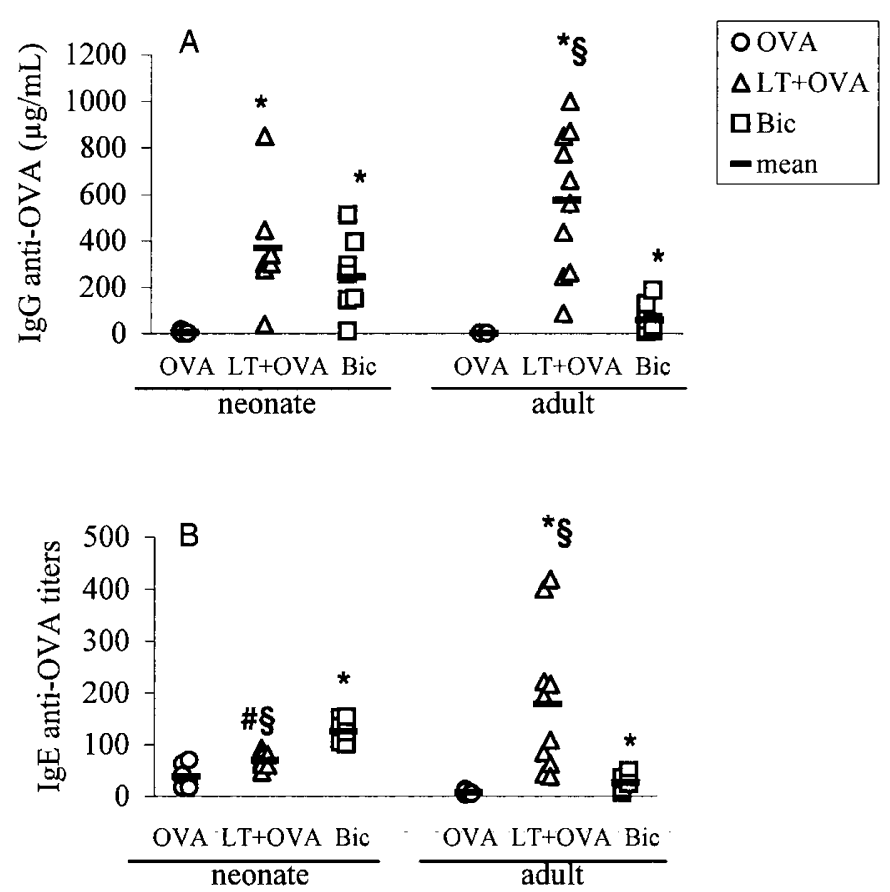

Figure 3. Systemic anti-OVA $\operatorname{IgG}(A)$ and $\operatorname{IgE}(B)$ responses in gnotobiotic mice monoassociated with $E$. coli at the neonatal stage (neonate) or at the adult stage $(a d u l t)$. Mice were treated and results are expressed as in Figure $1 .{ }^{*} p<$ $0.001,{ }^{*} p<0.05$ compared with the respective OVA-fed group, and $\S p<$ 0.001 compared with the respective Bic-fed group. were about 10 and 7 times greater than those of the Bic-fed group $(p<0.001)$, suggesting hyperstimulation of the $\mathrm{Ab}$ responses, which was not observed when $E$. coli was associated from birth on. Thus, a single strain of $E$. coli associated from birth on or at the adult stage did not prevent the LT-mediated abrogation of oral tolerance. However, its association from birth on may prevent the hyperstimulation of both $\operatorname{IgG}$ and $\operatorname{IgE}$ responses observed when it was associated in adults, suggesting a role of $E$. coli in regulation of immune responses in early life.

Protective effect of the gut microflora is associated with hyporesponsiveness of both OVA-specific IgG1 and IgG2a. To further investigate the mechanisms of protection of the gut microflora and clarify whether its protective effect influences the Th1/Th2 balance, OVA-specific IgG1 and IgG2a Ab levels were compared between mouse models colonized with the human or mouse gut microflora, either at the neonatal stage (models A and B) or at an adult stage (models C and D). A GF model (model E) was included for comparison.

As shown in Figure 4, in all mouse models a single oral dose of $20 \mathrm{mg}$ of OVA induced significant OVA-specific IgG2a and IgG1 hyporesponsiveness compared with the Bic-fed controls ( $p \leq 0.02$ and $p<0.001$, respectively). Similarly, both antiOVA IgG2a and IgG1 Ab levels in (LT + OVA)-fed mice colonized at the neonatal stage (models A and B) were significantly reduced compared with those in Bic-fed controls $(p<$ 0.05 and $p<0.01$, respectively), and no different from those in the OVA-fed mice. In contrast, in mice colonized at an adult stage (models C and D), (LT + OVA)-feeding resulted in a significant increase in both the anti-OVA IgG2a and IgG1 Abs compared with OVA-feeding $(p \leq 0.01)$. This pattern was also observed in GF mice (model E). Moreover, especially in model $\mathrm{C}$, such an increase was associated with IgG2a and IgG1 Ab levels, which tended to be higher than those in Bic-fed mice, as in GF mice (model E). Thus, a hyporesponsive state of both Th1- and Th2-controlled responses was maintained in presence of the gut microflora only when it was associated from birth on. 
IgG2a anti-OVA

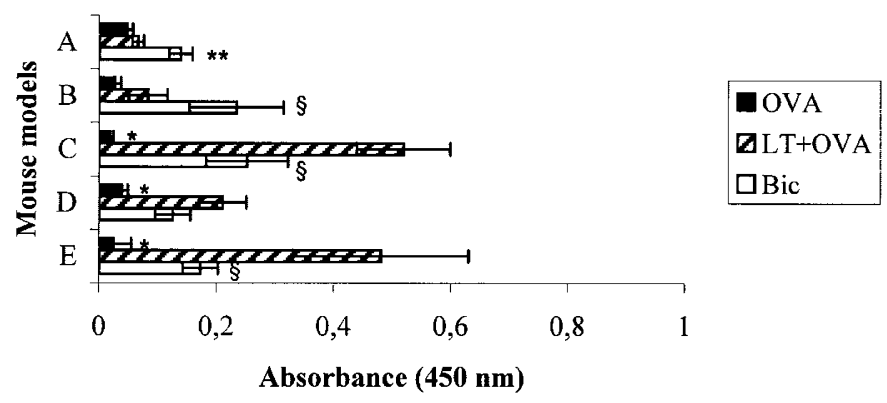

IgG1 anti-OVA

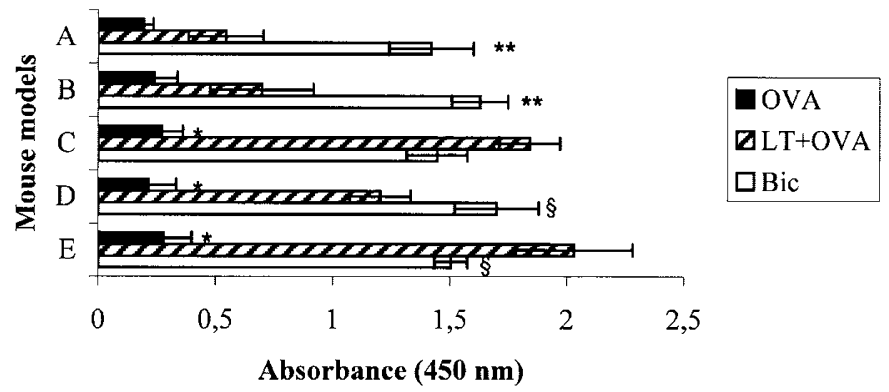

Figure 4. Systemic anti-OVA IgG2a and IgG1 responses $30 \mathrm{~d}$ post feeding in $\mathrm{CV}$ mice $(A)$, gnotobiotic mice colonized with human gut microflora either at neonatal $(B)$ or adult stage $(C)$, gnotobiotic mice colonized with mouse gut microflora at adult stage $(D)$ and in GF mice $(E)$. OVA-specific IgG2a and IgG1 were assayed by ELISA in serum from mice treated as in Figure 1. Data represent mean absorbances at 1:810 dilution \pm SEM from 7 to 10 mice per group. ${ }^{*} p<0.002,{ }^{* *} p \leq 0.01$, and $\S p \leq 0.05$ compared with the (LT + OVA)-fed group.

\section{DISCUSSION}

In the present study, using gnotobiotic mice colonized with human fecal flora, we showed that the human gut microflora can protect from the LT-mediated abrogation of oral tolerance to co-ingested OVA, as the suppression of serum specific $\mathrm{IgG}$, especially $\operatorname{IgG} 1$ and $\operatorname{IgG} 2 \mathrm{a}$, and $\operatorname{IgE} \mathrm{Ab}$ responses can still be observed. However, the protective role was only effective when the gut microflora was naturally associated from birth on, and it did not result from a single bacterial species predominant during the neonatal period.

We observed that the establishment of the gut microflora in early life was crucial for the protective effect against LTmediated abrogation of oral tolerance to co-ingested OVA, and similar results were observed with human and mouse microflora. Indeed, when the gut microflora was associated in mice at $5 \mathrm{wk}$ of age, its protective effect failed and results were similar to those in GF mice, as if the gut microflora still had no effect. It is known that gut microflora largely affects the full development and functions of the GALT (20), and several studies have indicated that the establishment of the gut microflora in the neonatal period could play a crucial role in determining immune regulation in the immune system $(13,21-25)$. Sudo et al. (21) have reported an age-dependent acquisition of full competence for GALT, inasmuch as the susceptibility of oral tolerance induction, especially the down-regulation of the
$\mathrm{IgE} \mathrm{Ab}$ response after OVA feeding, was restored in GF mice colonized with Bifidobacterium infantis at the neonatal stage, but not at an older age. The concept of establishing, in early life, mechanisms involved in regulating oral tolerance by the gut microflora is also confirmed in the present study, inasmuch as the colonization of the gut by the whole microflora or by a single strain of $E$. coli, either from birth on or at an adult stage, led to considerable differences in susceptibility of the host's immune responses to LT-mediated effect. On the other hand, it has been reported that postnatal maturation of the immune system requires a Th1-polarized immune deviation and the endogenous gut microflora, present after birth, could contribute to this maturation (22-24). We believe that crucial events for the appropriate functioning of GALT occur in the neonatal period, because they cannot occur later, and that the gut microflora is an important environmental parameter for regulatory effects and endogenous stimuli, as also recently shown by Hooper et al. (26) through overall changes in intestinal gene expression after colonization. In addition, one cannot exclude that the protective role of the gut microflora against LTmediated abrogation of oral tolerance might be due to effects on the parent immune system passed on to neonates, especially through maternal $\mathrm{Ab}$, immunosuppressive factors, and/or maternal lymphocytes present in maternal milk, as suggested by the recent review of Kelly and Coutts (27). However, the mechanisms involved and the relationships between gut microflora, passively acquired maternal factors, and neonatal intestinal immunity are still poorly defined.

One of our hypotheses was to test whether some of the bacterial species predominant in the neonatal period are involved in the protective role of the gut microflora and whether a single strain may be sufficient for protection. From a bacteriological point of view, the neonatal period is characterized by the bacterial colonization of the digestive tract that occurs naturally as of birth and follows a sequence up to complex and diversified composition, largely influenced by dietary diversification. Similar complex events occur in humans and mice $(28-32)$. However, early colonization of the gut is limited to very few bacterial species specifically present in large amounts in the digestive tract of mouse and/or human newborns. E. coli is one of the predominant genera in the gut of newborn infants and growing $\mathrm{CV}$ mice, and its level generally decreases at the adult stage $(28,30,31,33)$. For the first time, our data also showed that $E$. coli predominated in neonate gnotobiotic mice (i.e. preweaned 15-d-old mice) colonized with human gut microflora from birth on and decreased afterward. Previous studies in gnotobiotic mice on the role of the gut microflora on the immune system have shown that single bacterial species of intestinal origin can exert immunomodulatory effects and, depending on the immune responses studied, only these bacteria or the whole microflora are necessary to induce an immunomodulatory effect similar to that observed in $\mathrm{CV}$ mice (21, 34-36). Hence, it has been reported that strains of E. coli can maintain systemic anti-OVA IgG suppression induced after OVA feeding (36) or stimulate pro-inflammatory cytokine production by peritoneal macrophages (35), as does the whole mouse gut microflora. In these studies, bacterial colonization has been performed in adult mice. Moreover, as previously 
observed, Sudo et al. (21) have shown that a single bacterial strain of $B$. infantis is able to restore the anti-OVA IgE suppression as exerted by the whole microflora. Our results showed that $E$. coli monoassociated in neonate or adult GF mice did not protect oral tolerance from LT-mediated abrogation, suggesting that this bacterial strain cannot provide full protection. Similar results were obtained with a single strain of Lactobacillus sp., predominant in newborn mice (data not shown). Therefore, our results in monoassociated mice showed that a single strain does not provide enough stimulation for protection. On the other hand, other studies have shown that a complex microflora is necessary for full stimulation of the intestinal IgA immune system $(34,37)$. In fact, it has been reported in gnotobiotic mice colonized with gut microflora isolated from 1- to 25-d-old newborn mice that only the colonization with the complex flora from a weaned 25-d-old mouse resulted in an IgA plasmocyte number similar to that obtained in CV mice. These results show that the whole sequence of bacterial colonization in the young can be necessary to fully stimulate development of immune parameters, thus suggesting that a similar situation could explain our failure to reproduce with only one bacterial strain the protective role observed with the whole gut microflora. This hypothesis was also supported by results in gnotobiotic mice colonized with the human gut microflora from birth on, inasmuch as the number of bifidobacteria and lactobacilli dropped dramatically in these gnotobiotic mice but did not impair the potential protective effect of the human gut microflora. This suggests that neither of these two genera are involved in the protection, although predominant in the gut of human infants and newborn mice, respectively. On the contrary, the absence of protection in gnotobiotic mice colonized at the adult stage with the whole adult fecal microflora might have been related to an anarchical and drastic bacterial colonization of the gut. However, we can discard this hypothesis as the bacterial profiles were similar between adult gnotobiotic mice, i.e. 10-12-wk-old mice, colonized with the human microflora from birth on or at $5 \mathrm{wk}$ of age. Moreover, the composition of the gut microflora is stable at this particular stage of life, because it has been reported that the bacterial equilibrium of the gut microflora seems to be stabilized at around 6-7 wk of age in both $\mathrm{CV}$ and gnotobiotic mice (33). Similar results were obtained with human and mouse gut microflora, i.e. without heterogeneity between host and gut microflora origin, which strengthened our opinion that the natural sequential establishment of the gut microflora as of the neonatal period was more important for protection than the influence of specific bacterial species. This also underlined that gnotobiotic mouse models, which are good recipients of bacterial strains from heterologous species, especially human species (38), are appropriate models for our in vivo studies.

LT is described as a potent mucosal immunogen and adjuvant to orally co-administered $\mathrm{Ag}$ (as it abrogates oral tolerance to this specific Ag), which induces a mix of Th1/Th2 responses $(4,6-9,11)$. As shown by both IgG1 and $\operatorname{IgG} 2 \mathrm{a}$ responses, our results in the (LT + OVA)-fed gnotobiotic mice associated with gut microflora at an adult stage confirmed this dual Th1/Th2 response. It is interesting to note that this response was similar to that observed in GF mice, thus show- ing that the gut microflora, especially the human flora, was unable to stimulate any protective effect against LT when associated after the postnatal period. In addition, the partial suppression of the anti-OVA IgE response in these mice might have resulted from a Th2-skewed immune deviation in adults, as recently described in absence of the gut microflora $(24,25)$. To some degree, this hypothesis may also be supported by the $\operatorname{IgE}$ responses in E. coli monoassociated mice, as no hyperstimulation of the $\mathrm{Ab}$ response was observed when the bacterial strain was associated from birth on. In mice colonized with the gut microflora from birth on, in contrast to others, the protective effect of the gut microflora was associated with the maintained suppression of IgG2a, IgG1, and IgE Ab responses. This implies that the influence of the sequential establishment of the gut microflora in early life induces a regulation of both Th1- and Th2-controlled immune responses, which leads to protection later in life. However, the molecular mechanisms involved and the relationships between gut microflora and $\mathrm{T}$ cell subpopulations need to be further investigated. On the other hand, the $\mathrm{IgG}$ isotype-responses in mice fed with a single high dose of $20 \mathrm{mg}$ of OVA are consistent with studies indicating that both Th1 and Th2 subsets are equally susceptible to the induction of oral tolerance $(21,39,40)$. Our data also supported the hypothesis that the gut microflora did not directly influence induction of Th1- and Th2-dependent tolerance as $\mathrm{Ag}$-specific IgG2a and IgG1 hyporesponsiveness was observed in all the mice fed OVA, whatever the mouse models tested, i.e. $\mathrm{CV}$, gnotobiotic, and especially $\mathrm{GF}$.

$\mathrm{IgE} \mathrm{Ab}$ have been described to play a well-defined role in numerous human food-hypersensitivity symptoms, especially in children (41), and oral tolerance is believed to play a physiologic role in the suppression of IgE $\mathrm{Ab}$ to dietary proteins $(1,2)$. The observed divergence between IgG and IgE abrogation in (LT + OVA)-fed gnotobiotic mice suggested that the IgE response was more tightly regulated and less easily abrogated than the $\operatorname{IgG}$ response, thus confirming its marked susceptibility to induction of oral tolerance and its different regulation from that of $\operatorname{IgG}(42,43)$. In contrast, it might have been related to intrinsic properties of LT. Although LT induces both Th1- and Th2-type responses when used as a mucosal adjuvant, it did not induce high Ag-specific IgE response (8). Nonetheless, our data with the IgE response support accumulating evidence that early life and the presence of endogenous gut microflora in this period may reduce occurrence of food allergies $(13-15,24)$.

It has been recently recognized that multiple nonexclusive $T$ cell-mediated mechanisms are involved in oral tolerance (44) and the gut microflora is an important factor in modulating oral tolerance (20). As previously observed, it can regulate mechanisms of induction of oral tolerance, and the present data supported that at least some of these regulatory events must be induced in the neonatal period. In contrast, some regulatory effects influence long-term maintenance of oral tolerance (6, 36). These differences indicate that the interactions between gut microflora and mechanisms involved in the induction and maintenance of oral tolerance are very complex and not yet fully understood. 


\section{CONCLUSION}

In conclusion, this work provides evidence that the natural establishment of the gut microflora in the neonatal period crucially influences the normal and life-long development of intestinal immune functions. These data suggest that maintaining both the spectrum and sequence of implantation of gut microflora is important to the avoidance of food allergy.

\section{REFERENCES}

1. Strobel S, Mowat AM 1998 Immune responses to dietary antigens: oral tolerance. Immunol Today 19:173-181

2. Holt PG 1998 Mucosal immunity in relation to the development of oral tolerance/ sensitization. Allergy 53:16-19

3. Elson CO, Ealding W 1984 Cholera toxin feeding did not induce oral tolerance in mice and abrogated oral tolerance to an unrelated protein antigen. $\mathrm{J}$ Immunol 133:2892-2897

4. Clements JD, Hartzog NM, Lyon FL 1988 Adjuvant activity of Escherichia coli heat-labile enterotoxin and effect on the induction of oral tolerance in mice to unrelated protein antigens. Vaccine 6:269-277

5. Pierre P, Denis O, Bazin H, Mbongolo Mbella E, Vaerman JP 1992 Modulation of oral tolerance to ovalbumin by cholera toxin and its B subunit. Eur J Immunol 22:3179-3182

6. Gaboriau-Routhiau V, Moreau MC 1996 Gut flora allows recovery of oral tolerance to ovalbumin in mice after transient breakdown mediated by cholera toxin or Escherichia coli heat-labile enterotoxin. Pediatr Res 39:625-629

7. Douce G, Giannelli V, Pizza M, Lewis D, Everest P, Rappuoli R, Dougan G 1999 Genetically detoxified mutants of heat-labile toxin from Escherichia coli are able to act as oral adjuvants. Infect Immun 67:4400-4406

8. Takahashi I, Marinaro M, Kiyono H, Jackson RJ, Nakagawa I, Fujihashi K, Hamada S, Clements JD, Bost KL, McGhee JR 1996 Mechanisms for mucosal immunogenicity and adjuvanticity of Escherichia coli labile enterotoxin. J Infect Dis 173:627635

9. Martin M, Metzger DJ, Michalek SM, Connell TD, Russel MW 2000 Comparative analysis of the mucosal adjuvanticity of the type II heat-labile enterotoxins LT-IIa and LT-IIb. Infect Immun 68:281-287

10. Martin M, Metzger DJ, Michalek SM, Connell TD, Russel MW 2001 Distinct cytokine regulation by cholera toxin and type II heat-labile toxins involves differential regulation of CD40 ligand on CD4+ T cells. Infect Immun 69:4486-4492

11. Yamamoto M, McGhee JR, Hagiwara Y, Otake S, Kiyono H 2001 Genetically manipulated bacterial toxin as a new generation mucosal adjuvant. Scand J Immunol 53:211-217

12. Björksten B 1999 The intrauterine and postnatal environments. J Allergy Clin Immunol 104:1119-1127

13. Björksten B 1999 Environment and infant immunity. Proc Nutr Soc 58:729-732

14. Holt PG, Macaubas C, Prescott SL, Sly PD 1999 Microbial stimulation as an aetiologic factor in atopic disease. Allergy 54(suppl 49):12-16

15. Prescott SL 2001 The significance of immune responses to allergens in early life. Clin Exp Allergy 31:1167-1169

16. Coffman RL, Seymour BWP, Lebman DA, Hiraki DD, Christiansen JA, Shrader B Cherwinski HM, Savelkoul HFJ, Finkelman FD, Bond MW, Mosmann TM 1988 The role of helper $\mathrm{T}$ cell products in mouse B cell differentiation and isotype regulation. Immunol Rev 102:5-28

17. Andremont A, Raibaud P, Tancrède C 1983 Effect of erythromycin on microbial antagonisms: a study in gnotobiotic mice associated with a human fecal flora. J Infect Dis 148:579-587

18. Benno Y, Mitsuoka T 1992 Impact of Bifidobacterium longum on human fecal microflora. Microbiol Immunol 36:683-694

19. Hata K, Andoh A, Sato H, Araki M, Tanaka M, Tsujikawa T, Fujiyama Y, Bamba T 2001 Sequential changes in luminal microflora and mucosal cytokine expression during developing of colitis in HLA-B27/b2 microglobulin transgenic rats. Scand J Gastroenterol 36:1185-1192

20. Moreau MC, Gaboriau-Routhiau V 2001 Influence of resident intestinal microflora on the development and functions of the gut-associated lymphoid tissue. Microb Ecol Health Dis 13:65-86
21. Sudo N, Sawamura SA, Tanaka K, Aiba Y, Kubo C, Koga Y 1997 The requirement of intestinal bacterial flora for the development of an IgE production system fully susceptible to oral tolerance induction. J Immunol 159:1739-1745

22. Nicaise P, Gleizes A, Sandre C, Kergot R, Lebrec H, Forestier F, Labarre C 1999 The intestinal microflora regulates cytokine production positively in spleen-derived macrophages but negatively in bone marrow-derived macrophages. Eur Cytokine Net 10:365-372

23. Vieira PL, de Jong EC, Wierenga EA, Kapsenberg ML, Kalinski P 2000 Development of Th1-inducing capacity in myeloid dendritic cells requires environmental instruction. J Immunol 164:4507-4512

24. Oyama N, Sudo N, Sogawa H, Kubo C 2001 Antibiotic use during infancy promotes a shift in the Th1/Th2 balance toward Th2-dominant immunity in mice. J Allergy Clin Immunol 107:153-159

25. Sudo N, Yu XN, Aiba Y, Oyama N, Sonoda J, Koga Y, Kubo C 2002 An oral introduction of intestinal bacteria prevents the development of a long-term Th2skewed immunological memory induced by neonatal antibiotic treatment in mice. Clin Exp Allergy 32:1112-1116

26. Hooper LV, Wong MH, Thelin A, Hansson L, Falk PG, Gordon JI 2001 Molecular analysis of commensal host-microbial relationships in the intestine. Science 291:881884

27. Kelly D, Coutts AG 2000 Early nutrition and the development of immune function in the neonate. Proc Nutr Soc 59:177-185

28. Finegold SM, Sutter VL, Mathisen GE 1983 Normal indigenous intestinal flora. In: Hentges DJ (ed) Human Intestinal Microflora in Health and Disease. Academic Press, New York, pp 3-31

29. Kleessen B, Bezirtzoglou E, Mättö J 2000 Culture-based knowledge on biodiversity, development and stability of human gastrointestinal microflora. Microb Ecol Health Dis Suppl 2:53-63

30. Hopkins MJ, Sharp R, MacFarlane GT 2001 Age and disease related changes in intestinal bacterial populations assessed by cell culture, 16S rRNA abundance, and community cellular fatty acid profiles. Gut 48:198-205

31. Schaedler RW, Dubos R, Costello R 1965 The development of the bacterial flora in the gastrointestinal tract of mice. J Exp Med 122:59-66

32. Harris MA, Reddy CA, Carter GR 1976 Anaerobic bacteria from the large intestine of mice. Appl Environ Microbiol 31:907-912

33. Moreau MC, Corthier G, Muller MC, Dubos F, Raibaud P 1986 Relationship between rotavirus diarrhea and intestinal microflora establishment in conventional and gnotobiotic mice. J Clin Microbiol 23:863-868

34. Moreau MC, Ducluzeau R, Guy-Grand D, Muller MC 1978 Increase in the population of duodenal immunoglobulin A plasmocytes in axenic mice associated with different living or dead bacterial strains of intestinal origin. Infect Immun 21:532-539

35. Nicaise P, Gleizes A, Forestier F, Quero AM, Labarre C 1993 Influence of intestinal bacterial flora on cytokine (IL1, IL6 and TNF $\alpha$ ) production by mouse peritoneal macrophages. Eur Cytokine Netw 4:133-139

36. Moreau MC, Gaboriau-Routhiau V, Dubuquoy C, Bisetti N, Bouley C, Prevoteau H 1998 Modulating properties of intestinal bacterial strains, Escherichia coli and Bifidobacterium, on two specific immune responses generated in the gut, i.e. oral tolerance to ovalbumin and intestinal IgA anti-rotavirus response, in gnotobiotic mice. In: Talwar GP, Nath I, Ganguly NK, Rao KVS (eds) $10^{\text {th }}$ International Congress of Immunology, Monduzzi Editore, Bologna, pp 407-411

37. Moreau MC, Raibaud P, Muller MC 1982 Relationship between the development of the intestinal $\mathrm{IgA}$ immune system and the establishment of microbial flora in the digestive tract of young holoxenic mice. Ann Immunol (Paris) 133D:29-39

38. Raibaud P, Ducluzeau R, Dubos F, Hudault S, Bewa H, Muller MC 1980 Implantation of bacteria from the digestive tract of man and various animals into gnotobiotic mice. Am J Clin Nutr 33:2440-2447

39. Aroeira LS, Cardillo F, De Albuquerque DA, Vaz NM, Mengel J 1995 Anti-IL-10 treatment does not block either the induction or the maintenance of orally induced tolerance to OVA. Scand J Immunol 41:319-323

40. Garside P, Steel M, Worthey EA, Satoskar A, Alexander J, Bluethmann H, Liew FY $1995 \mathrm{~T}$ helper 2 cells are subject to high dose oral tolerance and are not essential for its induction. J Immunol 154:5649-5655

41. Sampson HA, Burks AW 1996 Mechanisms of food allergy. Annu Rev Nutr 16:161-177

42. Saklayen MG, Pesce AJ, Pollak VE, Michael G 1984 Kinetics of oral tolerance: study of variable affecting tolerance induced by oral administration of Ag. Int Arch Allergy Appl Immun 73:5-9

43. Moreau MC, Gaboriau-Routhiau V 1996 The absence of gut flora, the doses of Ag ingested and aging affect the long-term peripheral tolerance induced by ovalbumin feeding in mice. Res Immunol 147:49-59

44. Garside P, Mowat A 1997 Mechanisms of oral tolerance. Critical Rev Immunol 17:119-137 